\title{
A Comparison of Solar Power Systems (CSP): Solar Tower (ST) Systems versus Parabolic Trough (PT) Systems
}

\author{
Huseyin Murat Cekirge ${ }^{1}$, Ammar Elhassan ${ }^{2}$ \\ ${ }^{1}$ Department of Mechanical Engineering, Prince Mohammad Bin Fahd University, Al Khobar, KSA \\ ${ }^{2}$ Department of Information Technology, Prince Mohammad Bin Fahd University, Al Khobar, KSA
}

Email address:

hmcekirge@usa.net (H. M. Cekirge), aelhassan@pmu.edu.sa (A. Elhassan)

\section{To cite this article:}

Huseyin Murat Cekirge, Ammar Elhassan. A Comparison of Solar Power Systems (CSP): Solar Tower (ST) Systems versus Parabolic Trough (PT) Systems. American Journal of Energy Engineering. Vol. 3, No. 3, 2015, pp. 29-36. doi: 10.11648/j.ajee.20150303.11

\begin{abstract}
Comparison of Comparison of Solar Power System (CSP) power plants will be introduced and discussed; Solar Tower (ST) plants and Parabolic Trough (PT) plants are subjects of this comparison. The comparison will be made possibly analytical or quantitatively instead of qualitatively. Examples will be presented and explained in detail. The main issues such efficiency, area of the plant, environmental issues, molten salt storage, the cost of the plants, dust and humidity, maintenance and operation cost and total investment are discussed.
\end{abstract}

Keywords: Solar Tower Power, Parabolic Troughs, Comparison of CSP Power Plants, Environmental Impact of Solar Power, Environmental Impact of Parabolic Troughs, Raspberry Pi, Arduino, Arm Architecture

\section{Introduction}

Several Concentrated Solar Plants (CSP) are at the design, research and development phases, these are mainly, Parabolic Trough (PT), Solar Tower and Linear Fresnel systems. Design limitations combined with economic reasons mean that the building of Linear Fresnel Power systems was adjourned globally; therefore PT and Solar Tower systems will be compared in this study. Qualitative comparisons of these systems are presented in Table 1.

Table 1. Qualitative comparison of Solar Tower and PT systems.

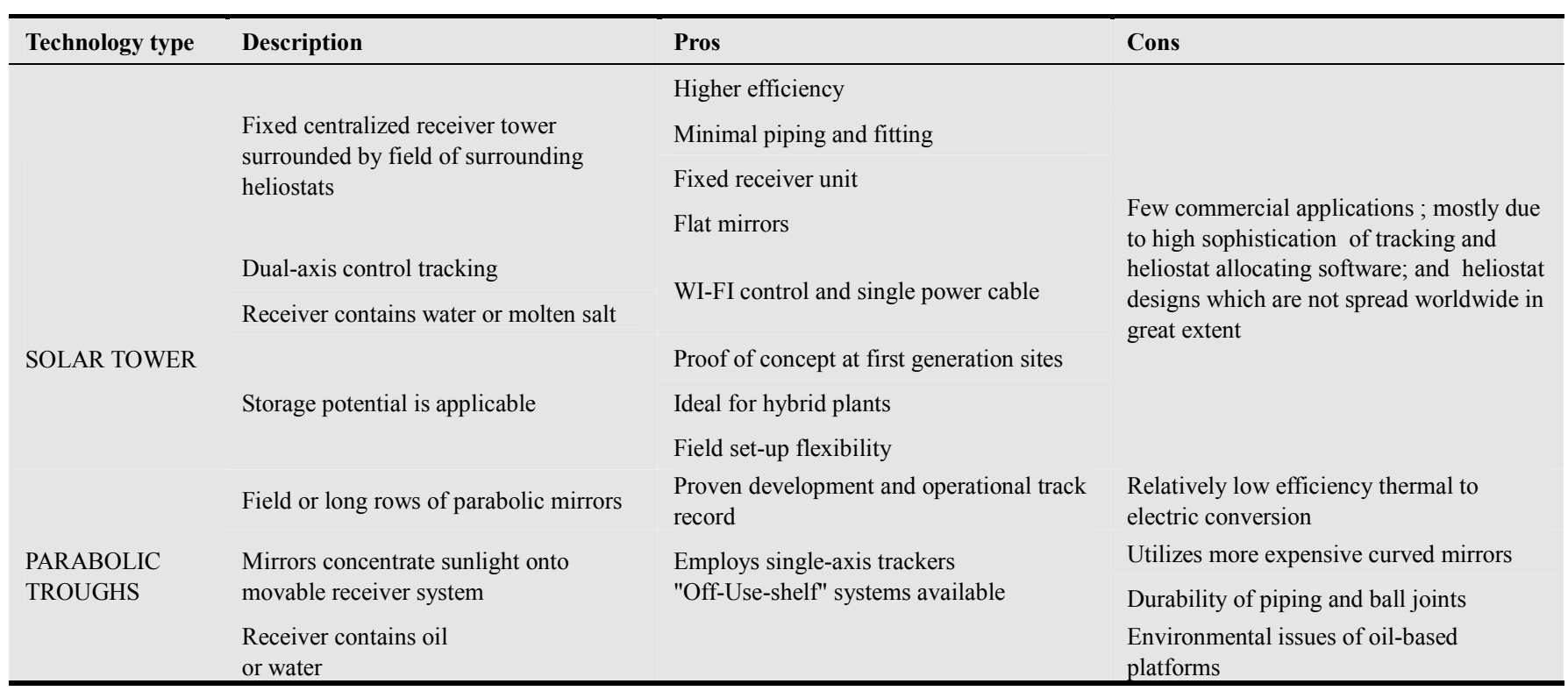


The reason of minimal commercial utilization of Solar Tower is the sophisticated tracking and control software and WIFI system cannot be offered by many commercial companies. PT's have implementation history in the renewable energy industry. PT's generate energy through heating of the transfer fluid. ST system is based on a number of heliostats and tower boiler, more efficient than the PT systems with the added bonus of not having toxic heat transfer fluid, and efficient use of storage using molten salt.

\section{Comparison of Solar Tower (ST) and Parabolic Troughs (PT)}

\subsection{Energy Calculations, ST and PT}

Considering an Integrated Power Plant, IPP, and Solar Tower can contribute all energy that is needed by the steam turbine, Figure 1, if enough land is provided for hosting the power plant structures.

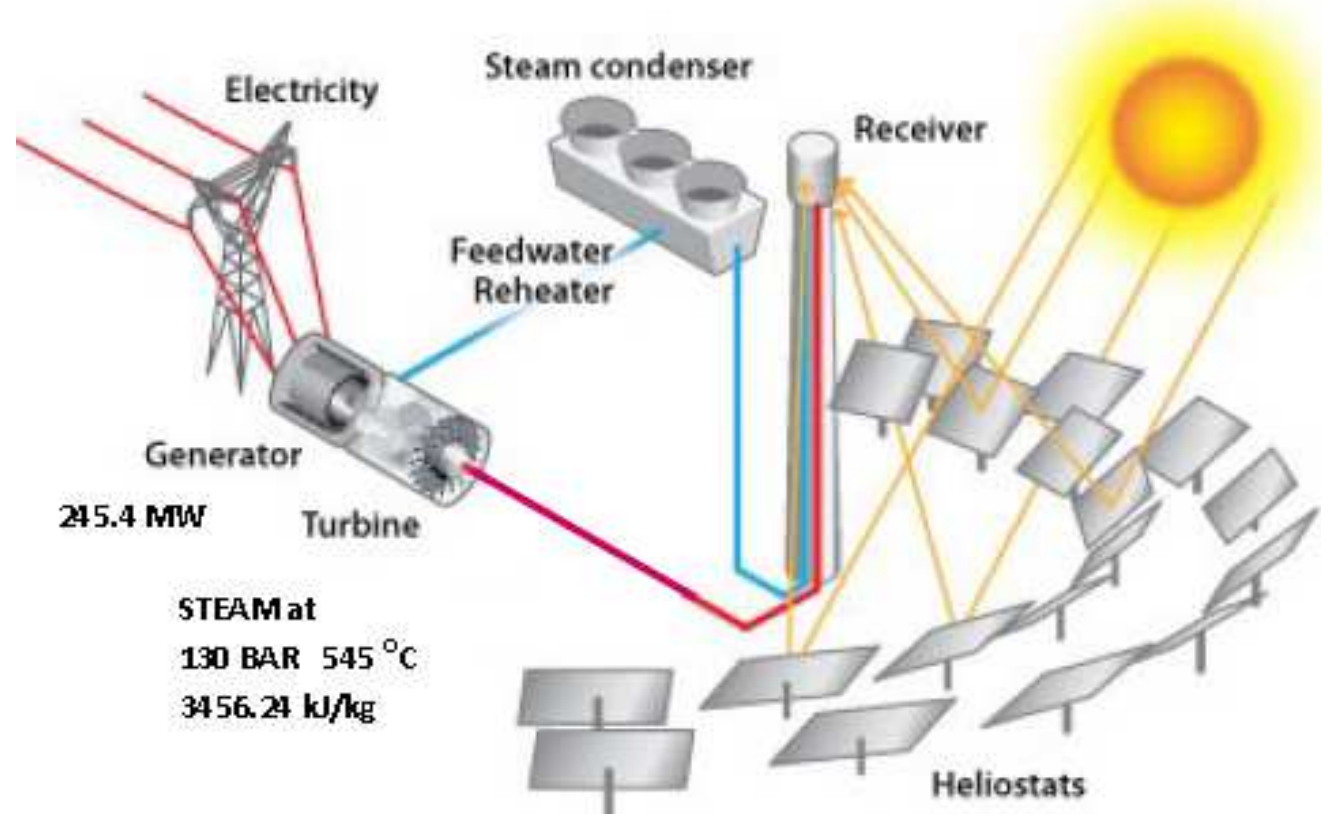

Figure 1. Steam goes to turbine directly from the Solar Tower, [1]

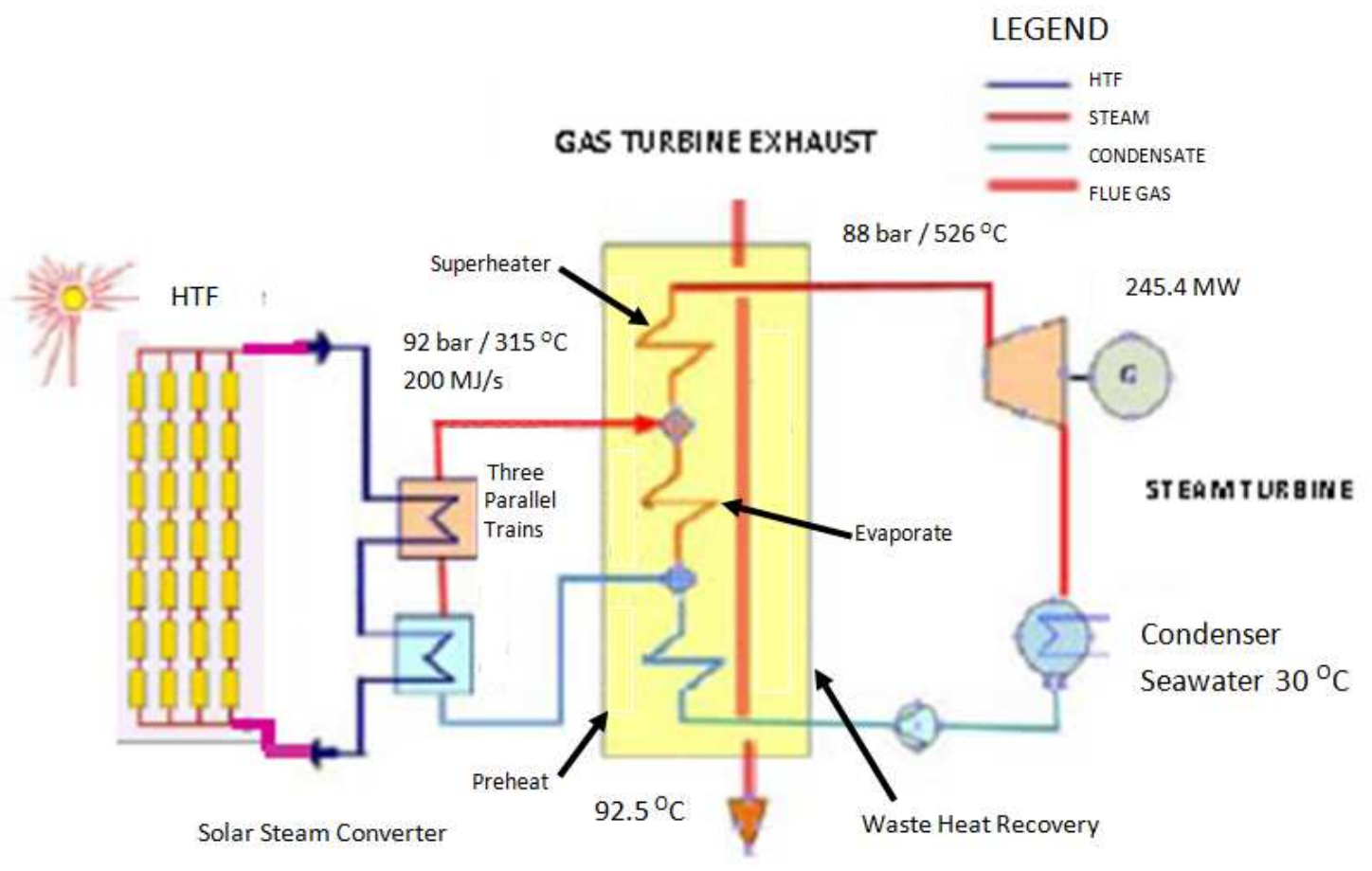

Figure 2. PT with Waste Heat Recovery Boiler, WHRB [1]. 
In the case of the PT system as in Figure 2, the contribution of solar power is $40 \mathrm{MW}$ and the thermodynamic calculations of enthalpy, entering to and exiting from Waste Heat Recovery Boiler WHRB, were made through [2]. The steam from the PT cannot be used without the utilization of a Waste Heat Recovery Boiler WHRB. As such, gross efficiency is reduced by approximately twenty percent because the heat transferring fluid, HTF, cannot exceed $400{ }^{\circ} \mathrm{C}$.

PT systems with thermal fluid are not as efficient as CSP Solar Tower systems (ST) that inject steam directly into the turbine; ST systems are approximately 30-40 percent more efficient. In Parabolic Trough type PT plant, the heat transfer is based on thermal oil which can be heated to no more than to $400^{\circ} \mathrm{C}$; and degrades and loses efficiency at higher temperatures.

Table 2. Thermodynamic calculations of Solar Tower, [2]

\begin{tabular}{llll}
\hline IPP_Solar_PT & & & \\
\hline Enthalpy_kJ/kg_(exit_pt)_at_bar_ & 92 & ${ }^{\circ} \mathrm{C}$ & 315 \\
Enthalpy_kJ/kg_(entrance_ST_turbine)_at_bar_ & 88 & ${ }^{\circ} \mathrm{C}$ & 526 \\
PT_power_mJ/s & 200 & & 3453.50 \\
Steam_turbine_output_MWe & 245.4 & \\
Total_energy_PT_MWe & 40.0 & \\
\hline
\end{tabular}

In the case study of a PT system, solar field is operated with a maximum temperature of $393{ }^{\circ} \mathrm{C}$; it delivers heat to the power block where the working fluid is water/steam using a couple of heat exchangers (HX's). At the exit of HX on the power block, the steam temperature measures $315^{\circ} \mathrm{C}$ and 92 bar pressure. The saturation temperature of dry steam at 92 bars is $305{ }^{\circ} \mathrm{C}$, i.e., steam is slightly superheated. In order to utilize steam in the

Table 3. Summary of results.

\begin{tabular}{lllll}
\hline Type & Group & Entry power MW & Steam & Useable MWe \\
\hline SOLAR ENERGY_PT & IPP & 200 & 92 BAR $315^{\circ} \mathrm{C}$ & 40 \\
SOLAR ENERGY_ST & IPP & 200 & 130 BAR $545^{\circ} \mathrm{C}$ & 66 \\
\hline
\end{tabular}

Turbine more efficiently, the temperature needs to be higher; therefore, the exhaust gas from the turbine, at $550{ }^{\circ} \mathrm{C}$, is utilized. The inlet steam of the steam turbine has a temperature of $526{ }^{\circ} \mathrm{C}$ at 88 bars. If we consider enthalpies of the steam both at superheated conditions,

$$
\begin{gathered}
\mathrm{h}\left(315^{\circ} \mathrm{C}, 92 \text { bar }\right)=2796.65 \mathrm{~kJ} / \mathrm{kg}, \\
\mathrm{h}\left(526^{\circ} \mathrm{C}, 88 \text { bar }\right)=3453.81 \mathrm{~kJ} / \mathrm{kg} .
\end{gathered}
$$

In other words, a difference of $657.16 \mathrm{~kJ}$ energy per $\mathrm{kg}$ of steam is produced by the exhaust gas in the waste heat recovery boiler. This kind of upgrade of solar heat is necessary in PT type installations in order to utilize the steam produced at $315^{\circ} \mathrm{C}$ in more efficient high temperature steam turbines. On the other hand, the exhaust gas of gas turbine with a temperature of $550{ }^{\circ} \mathrm{C}$; is sufficient to produce steam in the waste heat recovery boiler (WHRB) with the desired quality to be delivered to the steam turbine. This will be utilized power production without the need of solar generated steam. In addition to lower energy conversion efficiency, limited hybridization capability, long rows of pipes in the field necessary to transport heat transfer oil, and durability of movable heavy structures are taken into account for PT systems.

In the alternative, solar tower (ST) system, CSP plant is already available to produce steam directly deliverable to the high efficiency steam turbine with steam inlet conditions of 88 bars and $526{ }^{\circ} \mathrm{C}$ temperature. Therefore, in this scenario, gas turbine exhaust gas in the Waste Heat Recovery Boiler (WHRB) will produce the same quality steam with the ST CSP plant. This will improve the system performance by about $657 \mathrm{~kJ}$ per $\mathrm{kg}$ of steam circulating in the intermediate loop. As this is indicated in the block associated with PT plant, $200 \mathrm{MJ} / \mathrm{s}$ power requires about $71.5 \mathrm{~kg}$ steam circulation per second, i.e.,

$$
657 \mathrm{~kJ} / \mathrm{kg} \times 71.5 \mathrm{~kg} / \mathrm{s}=46975.5 \mathrm{~kJ} / \mathrm{s}=46.98 \mathrm{MW}
$$

of thermal power is lost due to the inclusion of low quality steam produced by PT system, Table 3 .

For implementation purposes, different schemes may be developed for better coupling of WHRB and Solar Tower with steam turbines. In these terms, various scenarios might be developed for comparisons.

\subsection{Comparison of Land Use ST Versus PT}

Land use refers to the land area directly occupied by a power plant structure, ST and PT, and is expressed in units of $\mathrm{m} 2 /(\mathrm{MWh} / \mathrm{y})$, that is square meter over megawatt hour per year. The visual impact indicating the area over which a power plant disturbs the landscape is measured in units of $\mathrm{m} 2 /(\mathrm{MWh} / \mathrm{y}))$. Both ST and PT systems are normally setup in remote areas with negligible visual impact. There is always misunderstanding that ST power plants require larger land areas, a typical land use of a ST is presented in Figure 3.

ST system has an algorithm to locate the heliostats in the 
field in an optimum way. Besides these algorithms are being tested and perfected in the field for efficient use of heliostat area, [3].

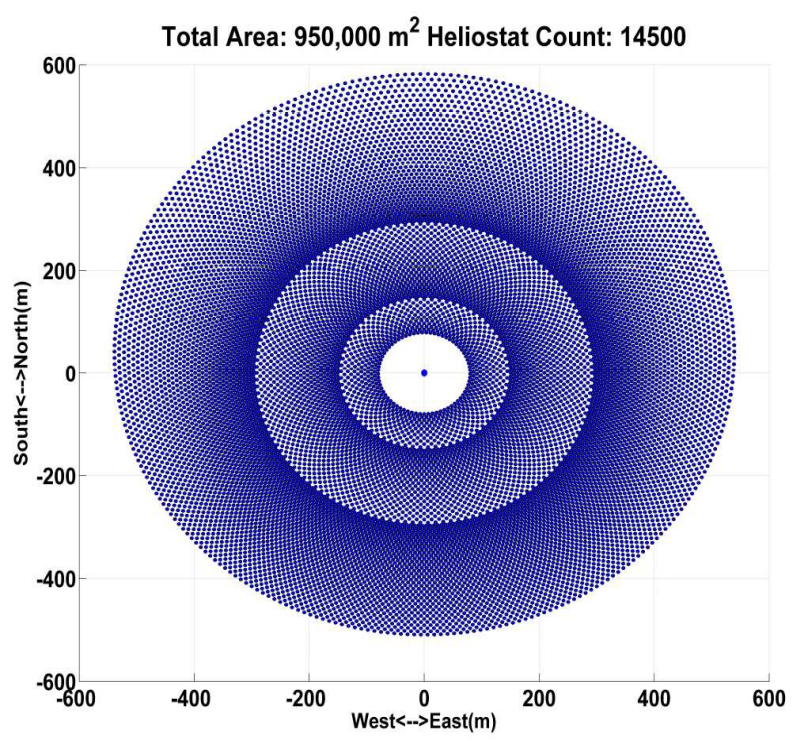

Figure 3. A Solar Tower, ST, "Heliostat" area. [4].

ST system can produce more power than PT system installed equivalent area. ST power system has higher efficiency since the control software has dominant factor to provide maximum solar energy input, [3], into solar power plant.

\section{Conventional Parabolic Trough}

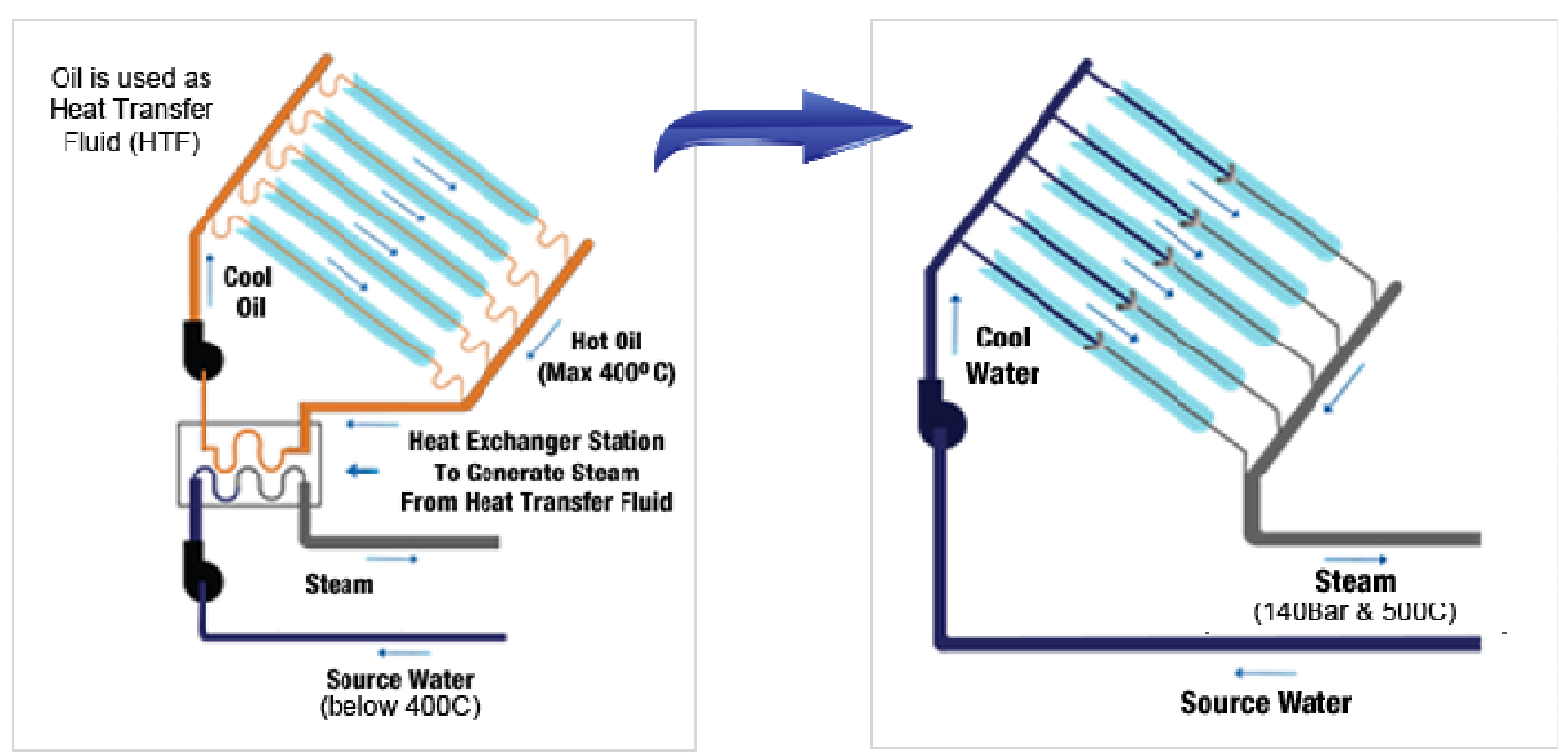

\subsection{Environmental Impact of ST Versus PT}

The potential environmental pollution risks relating to leaks or emissions of HTF (heat transfer fluids) impact soil, ground and surface water and air quality thus affecting human life. In the case of synthetic oil, as HTF, is used and compared to other possible HTFs, it is friendlier to the environment. PT systems consist of a widespread distribution of the receivers, i.e. tubes or fittings in the solar fields, thus increasing the risk of HTF leakages with the obvious environmental risks associated with it. This aspect is more problematic if the land/site area is not exclusive utilized by to the TES (thermal energy storage) subsystem and the process equipment. In this case, a higher pollution risk threatens the area if leakages of HTF occur in the storage system. There is also an unavoidable HTF odor in installations from leakages since the system has many pipes, fittings and ball joints. The synthetic oil, which it is highly toxic, can pollute the soil and could pass very rapidly to the water systems; MSDN of two HTFs can be found in [4] and [5]. This suggests that oil should be avoided in case of existing vulnerable aquifers. In ST based systems, this kind of pollution is not a factor.

For a solution of this problem in PT systems, steam should be obtained directly [6], which is not common practice, figure 4 illustrates. In these PT's, heat transfer fluid is replaced by water, Hittite Parabolic Toughs, Direct Steam Generation (DSG). The heat storage and efficiency solutions of this system are in development.

\section{HITTITE Parabolic Trough}

Figure 4. Direct steam generation (DGS), the Hittite PT's, [6].

Molten Salt for ST is less hazardous to the environment since again, HTF is not a factor in the heat exchange process. Water will be used for both systems for cleaning and there must be a source of water close to the plant. In the case of desalination, the water problem can be solved without any difficulty. In desert regions, dust is a high impact factor and hence, the CSP requires regular cleaning of the panel surfaces; this can be done by wipers and water spraying. The 
daily consumption of water for washing mirrors of ST is quite minimal. Humidity does not play an important role on the efficiency of ST power systems respect to PTs, since STs have flat surfaces.

Other environmental issues such as impact on wildlife have to be analyzed. For example, desert tortoises became a major factor and they were relocated during construction of the Ivanpah plant [7], risk to birds is very minimal and no more than the risk from windows and domestic cats [8]. Many bird mortalities apparently were caused by flight through the hot solar flux, burning feathers and beaks, and others are caused by hitting the heliostats, or anomalies in bird navigation habits.

\subsection{Maintenance of ST Versus PT}

PT systems consist of a number of pipes, fittings and connections, in other words the system is quite fragile. As an example: Daggett, 103 MW, PT Solar Power Station, located at Daggett, California, USA, the maintenance cost including parts, and excluding Thermal Exchange System, TES and Power Block as at May 2009 is : $\$ 1,289,786.00$. This number is quite high, even if loss of production during repairs is notwithstanding [9].
PT systems are made from a disparate set of materials including metal, glass and plastic which are highly susceptible to thermal load thus rendering these systems very fragile. The major problem for all CSP plants is the frequent breakage of expensive parabolic glass mirror panels which are manufactured using highly specialized fabrication processes. These issues must be eliminated, in order to reduce operation and maintenance $(\mathrm{O} \& \mathrm{M})$ costs. Also, heat receivers must be redesigned to decrease (O\&M) costs of the whole system by abandoning traditional "metal to glass attachments".

Maintenance costs are estimated at around fifteen percent in the favor of ST systems over PT systems, Figure 5 illustrates. It can be seen that breakdown risks are higher in the case of PT systems thus causing loss of income from total production, [10].

\subsection{Investment of ST Versus PT}

Tables 4 and 5 are show investments costs and returns from ST and PT systems. It can be seen that the initial investment for ST is 16 percent less than PT for a typical 100 MW plant. If the storage facilities are considered, the PT system is 42 percent more costly, [11], for the same size plant.

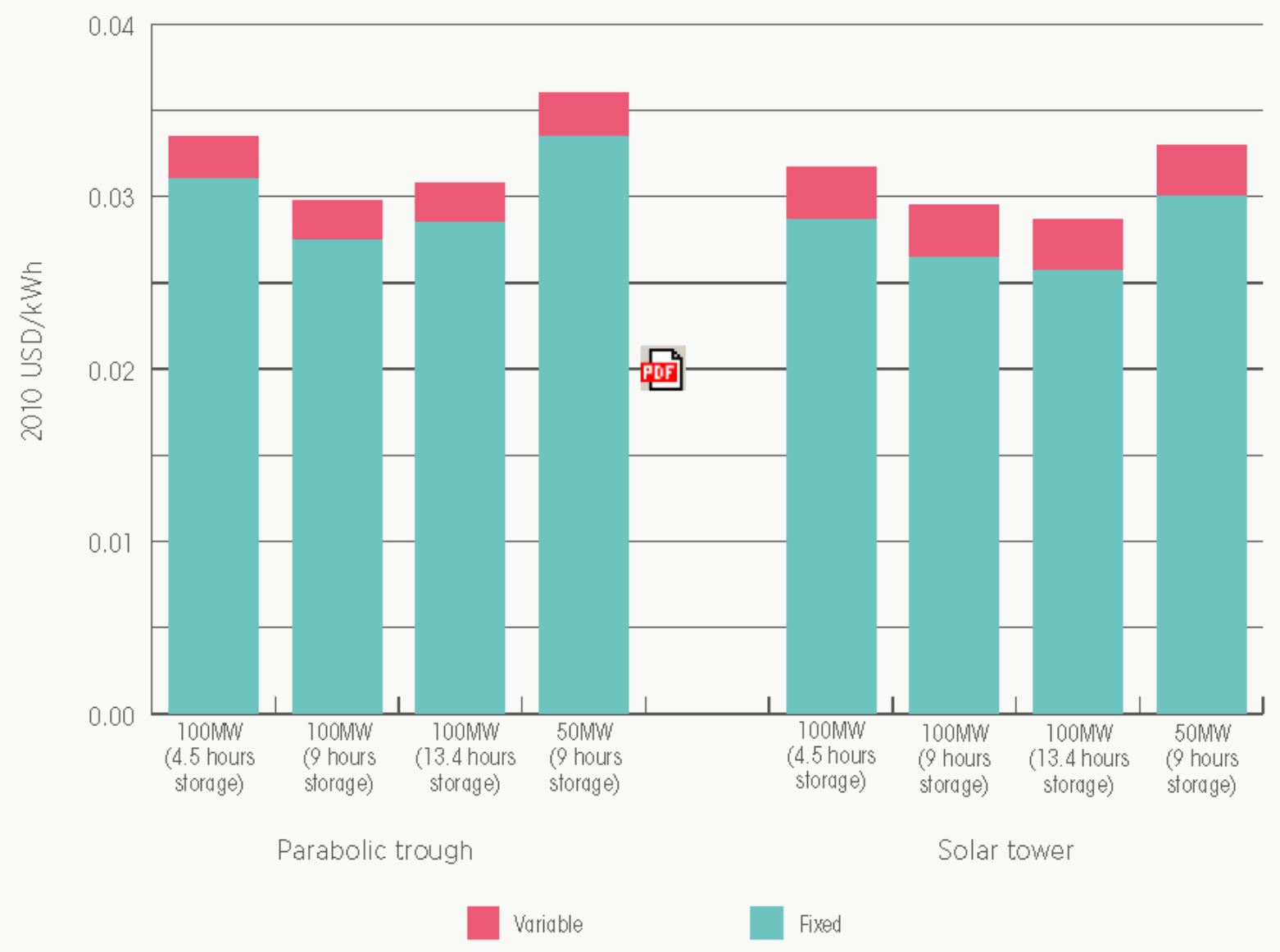

Figure 4. Operations and maintenance costs for PT and ST, [10]. 
Table 4. Current and projected plant cost for 100 MWe power tower with 6 hours storage at Longreach, Queensland, (unit costs based on power tower road map, [12]).

\begin{tabular}{|c|c|c|c|c|c|}
\hline All costs in AUD 2010 & $\begin{array}{l}\text { Current } \\
\text { Cost }\end{array}$ & Future Cost (2010) & Generic plant sizing & Current Capital Cost & Future Capital Cost (2020) \\
\hline Site Improvements $\left(\$ / \mathrm{m}^{2}\right)$ & 27 & 27 & $1,010,046 \mathrm{~m}$ & $\$ 27,422,752$ & $\$ 27,422,752$ \\
\hline Solar Field $\left(\$ / \mathrm{m}^{2}\right)$ & 217 & 130 & $1,010,046 \mathrm{~m}^{2}$ & $\$ 219,382,013$ & $\$ 131,629,208$ \\
\hline Receiver \& Tower $\left(\$ / \mathrm{kWh}_{\mathrm{th}}\right)$ & 217 & 185 & $507353 \mathrm{kWh}_{\text {th }}$ & $\$ 110,197,072$ & $\$ 93,667,511$ \\
\hline Storage $\left(\$ / \mathrm{kWh}_{\mathrm{th}}\right)$ & 33 & 22 & $1,691,180 \mathrm{kWh}_{\text {th }}$ & $\$ 55,098,644$ & $\$ 36,732,430$ \\
\hline Power Block $\left(\$ / \mathrm{kW}_{\mathrm{e}}\right.$ gross $)$ & 1086 & 869 & $115,000 \mathrm{~kW}_{\mathrm{e}}$ & $\$ 124,890,000$ & $\$ 99,912,000$ \\
\hline $\mathrm{BOP}\left(\$ / \mathrm{kW}_{\mathrm{e}}\right.$ gross $)$ & 380 & 272 & $115,000 \mathrm{~kW}_{\mathrm{e}}$ & $\$ 43,711,500$ & $\$ 31,222,500$ \\
\hline Indirect Cost & & & $35 \%$ & $\$ 203,245,693$ & $\$ 147,205,240$ \\
\hline Indicative Cost $\left(\$ / \mathrm{kW}_{\mathrm{e}}\right.$ net $)$ & & & & $\$ 7,836$ & $\$ 5,675$ \\
\hline O\&M (\$/kW-yr) & 71 & 54 & $100.05 \mathrm{MW}_{\text {net }}$ & $\$ 7,062,530$ & $\$ 5,432,715$ \\
\hline Solar Multiple & & & 1.8 & & \\
\hline Storage Hours & & & 6 & & \\
\hline Capacity Factor (\%) & & & 40.9 & & \\
\hline $\begin{array}{l}\text { LCOE }(\$ / M W h) \\
(20 \text { yr life, WACC 7\%) }\end{array}$ & & & & $\$ 226$ & $\$ 164$ \\
\hline
\end{tabular}

Table 5. Current and projected plant cost for $100 \mathrm{MW}$ parabolic trough plant at Longreach, Queensland, current and future unit costs based on, [13], and parabolic trough road map respectively, [14].

\begin{tabular}{|c|c|c|c|c|c|}
\hline All costs in AUD 2010 & Current Cost & Future Cost(2017) & Reference plant sizing & Current Capital Cost & $\begin{array}{l}\text { Future Capital } \\
\text { Cost (2017) } \\
\end{array}$ \\
\hline Site Improvements ( $\$ / \mathrm{m} 2)$ & 27 & 27 & $918,026 \mathrm{~m}$ & $\$ 24,786,702$ & $\$ 24,786,702$ \\
\hline Site Improvements ( $\$ / \mathrm{m} 2)$ & 320 & 217 & $918,026 \mathrm{~m} 2$ & $\$ 293,768,320$ & $\$ 199,211,642$ \\
\hline Solar Field $(\$ / \mathrm{m} 2)$ & 98 & 46 & $918,026 \mathrm{~m} 2$ & $\$ 89,966,548$ & $\$ 42,229,196$ \\
\hline Storage ( $\$ /$ kWhth) & 87 & 29 & $1,877,110 \mathrm{kWhth}$ & $\$ 163,308,570$ & $\$ 54,436,190$ \\
\hline Power Block, BOP ( $\$ /$ kWe gross) & 1021 & 884 & $111,000 \mathrm{kWe}$ & $\$ 113,331,000$ & $\$ 98,124,000$ \\
\hline Indirect Cost & $18.50 \%$ & $16 \%$ & & $\$ 126,754,811$ & $\$ 70,334,032$ \\
\hline Indicative Cost ( $\$$ kWe net) & & & & $\$ 8,119$ & $\$ 4,891$ \\
\hline O\&M (\$/kW-yr) & 80 & 51 & 100 MWnet & $\$ 7,980,000$ & $\$ 5,130,000$ \\
\hline Solar Multiple & & & 2 & & \\
\hline Storage Hours & & & 6 & & \\
\hline Capacity Factor (\%) & & & $43.20 \%$ & & \\
\hline $\begin{array}{l}\text { LCOE }(\$ / M W h) \\
(20 \text { yr. life, WACC 7\%) }\end{array}$ & & & & $\$ 223$ & $\$ 135$ \\
\hline
\end{tabular}

\section{Solar Tracking Sub-System}

To maintain maximum efficiency of the system, it is imperative to keep the solar panels pointing towards the sun for as long as possible. There are several methods for achieving this task, varied by cost and complexity. It is proposed that the use of the new breed of ARM-Architecture $[16,17]$ microcomputers such Arduino [15] and Raspberry Pi [18] coupled with one of three methods of calculating sun location and ray direction. In both cases below, we propose that solar panels be mounted on motors/actuators that are controlled via relays and microcomputers in addition to a power source (photovoltaic panel or power grid) to power the motors.

\subsection{GPS Based Calibration}

In this method, the microcomputer with its GPS and Compass sensors will be programmed with the necessary 
calibration code to position each solar panel at the correct angle for maximum exposure to sunlight. The cost of this approach is probably the least but only after the algorithm to track in relation to the GPS sensors has been written correctly.

\subsection{Voltage Differential Based Calibration}

By using twin solar panels mounted at right angle to each other, it is possible to read the two harvested voltage values from them and the microcomputer controlled motor/actuator is powered to rotate the platform such that the 2 voltage values from the two solar cells are kept with minimum differential thus guaranteeing that they are pointed at the sun in an optimum way. The cost of this method is higher because it uses two mirrors and requires voltage differential sensors.

\subsection{Image Based Calibration}

By utilizing a Raspberry Pi with a webcam, it is possible to track the location of the sun in the sky using an algorithm to take snapshots of the sky or of a bar shadow [19] and contrast them and rotate the platform accordingly [20] and [21]. The cost of this approach is in-line with the method in 3.1, although this technique has the advantage of being well documented and tested.

\section{Conclusions}

Solar thermal power plant technologies are important sources for providing a significant part of the clean and renewable energy needed in the future. Among these technologies, the qualitative comparison was made between ST systems and PT systems. It has been shown that the ST systems are superior to PT systems in various aspects including:

- ST systems are more efficient, at least 30 percent

- Land area per energy output is 20 to 30 percent in favor of ST systems

- No pollutants or environmentally hazardous materials are utilized in ST systems, hence the energy produced to pollution ratio is much higher

- Operating and Maintenance expenses are around 15 to 20 percent less in ST systems

- Without heat storage sub-systems, ST systems require 15 to 20 percent less upfront investment when considering output based calculations of ST and PT plants. With storage sub-system factored in, this figure is around 30 to 40 percent in favor of ST systems.

At the moment; ST systems are not being commercialized in wide extent, since technology of software and hardware of ST systems are in the hands of few commercial establishments. The software is the major factor; specifically solar tracking and heliostat allocating algorithms are needed to run ST system efficiently; however it is being possessed by limited number of organizations. In addition to all these factors, the ST systems can fit many climatic and geographic conditions.

\section{References}

[1] S. Erturan, Presentation of Greenway Solar, Istanbul, (http://greenwaycsp.com), 2014.

[2] Michael J. Moran and Howard N. Shapiro, Fundamentals of Engineering Thermodynamics, 6th Edition, John Wiley \& Sons, New Jersey, 2008.

[3] S. Erturan, Greenway, private communication, 2015.

[4] Paratherm, Heat Transfer Fluid, MSDS No. 144392405531120-5149421-102103, 30 October 2014.

[5] MultiTherm IG-1, Heat Transfer Fluid, MultiTherm LLC, January 1, 2013.

[6] O. Capan, Hittite, private communication, (http://www.hittitesolarenergy.com), 2015.

[7] Ivanpah Brightsource

Plant, (http://www.brightsourceenergy.com/ivanpah-solarproject\#.VS4AvPmUd8E), 2015.

[8] J. Desmond, BrightSource, private communication, 2015.

[9] C. Turchi, Parabolic Trough Reference Plant for Cost Modeling with the Solar Advisor Model, NREL, Boulder, CO, 2010.

[10] Concentrating Solar Power, Renewable Energy Technologies: Cost Analysis Series, Volume 1: Power Sector Issue 2/5, IRENA, International Renewable Energy Agency June 2012.

[11] Jim Hinkley, Bryan Curtin, Jenny Hayward, Alex Wonhas (CSIRO), Rod Boyd, Charles Grima, Amir Tadros, Ross Hall, Kevin Naicker, Adeeb Mikhail (Aurecon Australia Pty Ltd), Concentrating solar power - drivers and opportunities for cost-competitive electricity, CSIRO, March 2011.

[12] C. Turchi, M. Mehos, C. K. Ho, and G. J. Kolb, Current and future costs for parabolic trough and power tower systems in the US market. SolarPACES 2010. Perpignan, France, 2010.

[13] C. Kutscher, M. Mehos, C. Turchi, And G. Glatzmaier, LineFocus Solar Power Plant Cost Reduction Plan, NREL and Sandia, 2010.

[14] G. J. Kolb, C. K. Ho, T. R. Mancini and J. A. Gary, Power tower technology roadmap and cost reduction plan. Sandia National Laboratories (Draft, Version 18, December 2010), 2010 .

[15] Arduino, (www.arduino.cc), 2015.

[16] ARM Processors (http://www.arm.com/products/processors), 2015.

Guide,

[17] ARM Architectur, (https://www.scss.tcd.ie/ waldroj/3d1/arm_arm.pdf), 2015.

[18] Raspberry Pi, (https://www.raspberrypi.org), 2015.

[19] H. Arbab, B. Jazi, M. Rezagholizadeh, A computer tracking system of solar dish with two-axis degree freedoms based on picture processing of bar shadow, Renewable Energy, $34: 1114-1118,2009$. 
[20] R. Abd Rahim, M. N. S. Zainudin, M. M. Ismail, M. A. Othman, Image-based Solar Tracker Using Raspberry Pi Journal of Multidisciplinary Engineering Science and Technology (JMEST) ISSN: 3159-0040, Vol. 1 Issue 5, December-2014.
[21] P. Omar Badran and Ismail Arafat, The Enhancement of Solar Distillation using Image Processing and Neural Network Sun Tracking System International Journal of Mining, Metallurgy \& Mechanical Engineering (IJMMME) Volume 1, Issue 3 (2013) ISSN 2320-4052; EISSN 2320-4060, 2013. 